\title{
Letters
}

\section{Campaign to revitalise academic medicine}

\section{Crisis in UK academia affects academic medicine too}

EDITOR-Academic medicine is in a woeful state. $^{1-3}$ But this is only part of the crisis affecting UK academia as a whole. Pumping funds into academic medicine alone ${ }^{1-4}$ without tackling fundamental issues would only worsen the situation.

"Top class researchers make excellent teachers, and students benefit from the enhanced quality of the education they receive." ${ }^{5}$ But the assessment of these two core university activities, by the research assessment exercise (RAE) and the Quality Assurance Agency's audit and review processes respectively, is totally separate, generating serious conflict. Carrying such immense funding implications compared with the Quality Assurance Agency's process, the research assessment exercise wins over education every time. That clinical practice is assessed by a third process only increases the tension, so the saying "a successful clinical academic is one who doesn't see patients" becomes a truism and not just a pathetic old joke.

Preparing for the next research assessment exercise, research staff are being offered inducements to remain in post, and for institutions hoping to do better " 100 new chairs [have been] created in a bid to lift RAE scores." ${ }^{, 5}$ Universities are also shedding staff who are inevitably not so research competitive because of their contribution to education and clinical practice. This cullnow cyclical-creates a hostile environment that is devastating to morale, damages education, and wrecks research teams.

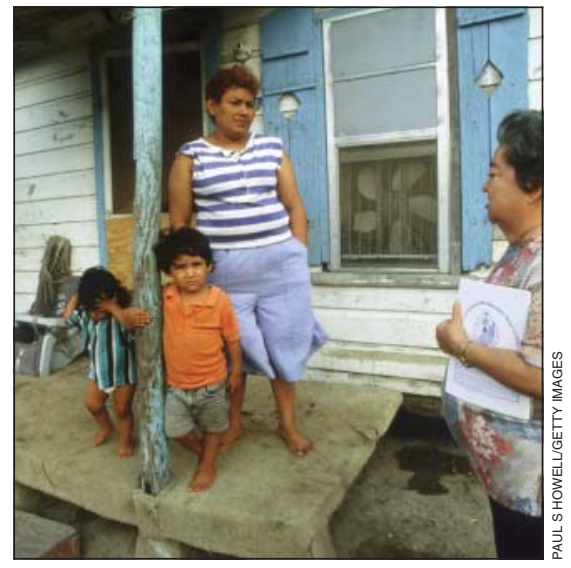

Academic medicine should be focused on health care
The conflict between service, education, and research is old but lies at the heart of the academic crisis and our leaders have let us down by failing to grapple with it. Linking the assessment of academic activities that are currently treated entirely separately is crucial. Only then can the natural synergy between education, research, and clinical work that originally attracted many people into academia be regained. Without it, UK academia will continue to deteriorate.

Alistair R Fielder professor of ophthalmology Department of Visual Neuroscience, Imperial College, Room 9L02, Charing Cross Campus, London W6 8RP

a.fielder@imperial.ac.uk

Michael Levin professor of paediatrics

Gareth Tudor-Williams senior lecturer in paediatric infectious diseases

Department of Paediatrics, Imperial College, London W2 1PG

Competing interests: AF is an institutional auditor for the Quality Assurance Agency.

1 Bell $\mathrm{J}$, on behalf of the working group of the Academy of Medical Sciences. Resuscitating clinical research in the United Kingdom. BMJ 2003;327:1041-3.

2 Stewart PM. Improving clinical research. $B M$ 2003;327:999-1001.

3 Clark J, Smith R. BMJ Publishing Group to launch an international campaign to promote academic medicine. BMJ 2003;327:1001-2

4 Correspondence. Academic medicine: time for reinvention. BMJ 2004;328:45-9. (3 January.)

5 Johnston C, Farrar S. 100 new chairs created in bid to lift RAE scores. Times Higher Educational Supplement 2003 Dec 12.

\section{Isolation hinders academic medicine}

EDITOR-I spent 30 years in an academic experiment devoted to promoting "community oriented medicine" and saw that the direction of academic medicine was not going to change if left in the hands of the academics. ${ }^{12}$ I then moved to health service management, which has allowed much room for thought about the role of academic medicine today.

Firstly, in the main, academic medicine is controlled by groups needing to replicate themselves.

Secondly, nobody asks the "consumers" of health care what they would expect academic medicine to be doing.

Thirdly, academic reward is usually unrelated to relevant needs of medicine and health care, the number of papers and quality of methods being the determinants.

Fourthly, a true alliance of academicians, politicians, economists, and consumers should look at where academic medicine needs to go.
Basil Porter medical director

Southern Region, Maccabi Health Services, PO Box 69 , Beersheva basilporter@hotmail.com

Competing interests: None declared.

1 Tugwell P. Campaign to revitalise academic medicine kicks off. BMJ 2004;328:597. (13 March.)

2 Porter B, Seidelman W. The politics of reform in medical education and health services. New York: Springer, 1992.

\section{Funding needs to be on the discussion} table

EDITOR-I was disappointed at the statement in Tugwell's editorial on the campaign to revitalise academic medicine that deals with how to tackle current failures. ${ }^{1} \mathrm{He}$ mentions working within current economic constraints and giving preference to strategies that call for no additional funding.

A false entrepreneurial approach, in which the output of health care and medical science is measured in monetary units driven by immediate clinical productivity, could be argued as the cause of many of the problems of academic medicine. It has diverted the efforts of faculty members away from research and teaching and weakened their capacity to continue delivering them with high quality. I call this approach false entrepreneurial because it ignores the benefits to society that accrue from the training and successful careers of the "endangered species" of doctor scientists.

If society agrees that medical progress is to its benefit, the mechanisms for the funding of its infrastructure need to be on the table for discussion. Figuring out a mechanism for funding of the academic enterprise will entail political posturing and argument. Perhaps it is time for academic doctors and scientists to take a stand beyond the one they have become used to-that is, finagling within the constraints of available resources to deliver an increasingly mediocre product.

I would be delighted to participate in this initiative if it were to redefine and reframe the enterprise of academic medicine, budget its cost, and devise the mechanisms to fight for its appropriate funding.

Fernando Elijovich fellow, American Heart Association

Center for Hypertension and Cardiovascular Medicine, Lenox Hill Hospital, New York, NY 10021, USA

felijovich@lenoxhill.net

Competing interests: FE is lecturer and consultant for several pharmaceutical companies.

\footnotetext{
1 Tugwell P. Campaign to revitalise academic medicine kicks off. BMJ 2004;328:597. (13 March.)
} 


\section{Focus on health care is needed}

EDITOR-Tugwell announces the campaign to revitalise academic medicine. ${ }^{1}$ I firmly believe that many academic leaders are not necessarily the role models or even the clinical leaders they should be. In particular, although many are outstanding scientists in a branch of the biomedical or even clinical sciences, it is rare for them to bring a truly academic perspective to their clinical work. That is, they rarely apply the rigorous principles of science to their clinical work, by questioning established dogma, testing new ways of doing things, or even evaluating clinical practices.

Without leadership in clinical work I believe that academic medicine is doomed to becoming increasingly less relevant to health care and more focused on biomedical science. Biomedical science is important, but I question whether biomedical scientists should be the academic medical leaders, with their attention elsewhere and not directly on improving health and health care and teaching others how to do this.

Paddy A Phillips head of medicine

Flinders University, Adelaide, SA 5042, Australia paddy.phillips@flinders.edu.au

Competing interests: None declared.

Tugwell P. Campaign to revitalise academic medicine kicks off. BMJ 2004;328:597. (13 March.)

\section{Academic medicine needs teeth}

EDITOR-Tugwell describes the campaign to revitalise academic medicine. ${ }^{1}$ Many doctors are not able to treat the increasingly common problems seen in primary care. These include depression, anxiety (especially social anxiety), alcohol excess, other drug problems, chronic pain, and many other complex problems.

Health systems are good at managing the problems of the 1960s and the problems the current managers and teachers fear or perhaps already have, but not the problems of young, poor, and disempowered people.

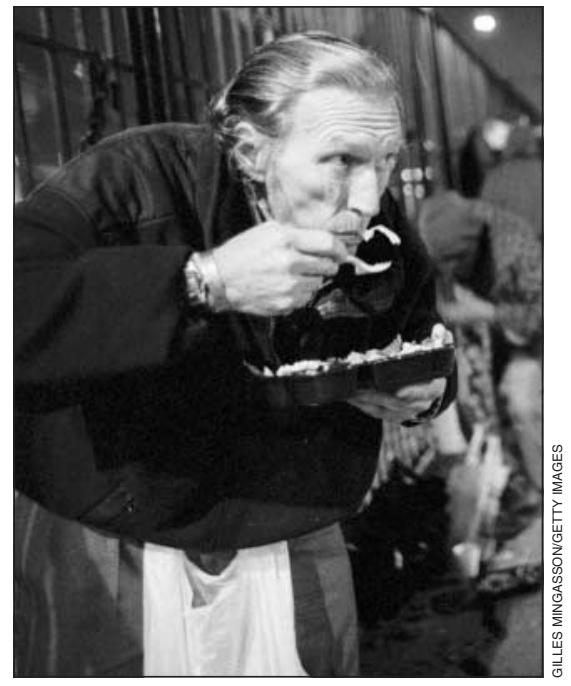

Health systems are not good at managing problems of disempowerment
In some of these fields-particularly alcohol problems and addiction to benzodiazepines and prescription opiates-doctors are too often the problem."

Ten minute consultations in general practice, and stays of 2.4 days in a hospital bed, hardly serve to promote the science and art of managing complex and often chronic problems well. This approach is designed to prop up a fragmented, technology oriented, illness treatment system through which some are helped and most are disadvantaged.

Universities are preoccupied (perhaps rightly, in the current political climate) with financial matters, first and foremost. Online teaching, the apparent saviour of medical education, will only worsen the issue. Good medical practice needs to be shown, empathy needs to be taught. Engagement does not occur online, and good data, although essential, are the least important part of medical education.

Some years ago I was part of a committee that recommended that mental health never be taught in tertiary care settings. It is still usual practice as it is convenient and cheap, serving only to scare students away and ensure that they are never exposed to the mental health problems that are most common in general practice. It is rather symptomatic of the whole training problem.

Rod MacQueen clinical director

Drug and Alcohol Services, Mid Western Area Health Service, Bloomfield Hospital, Orange, NSW 2800, Australia

rod.macqueen@mwahs.nsw.gov.au

Competing interests: None declared.

1 Tugwell P. Campaign to revitalise academic medicine kicks off. BMJ 2004;328:597. (13 March.)

2 Martyres RF, Clode D, Burns, JM. Seeking drugs or seeking help? Escalating "doctor shopping” by young heroin users before fatal overdose. Med J Austr 2004;80:211-4.

\section{Direction of academic medicine is worrying}

EDITOR-Three things concern me about the direction of academic medicine. ${ }^{1}$

Firstly, coordination of global concerns seems to be lacking in academic medicine. Diverse groups advocate for their causes, but there is no central organisation. For example, does a central group try to keep track of sanitation and public health data for various areas of the world? Does academic medicine leave this to the United Nations or does the academic community try to help the United Nations to organise the data? Does anyone track progress? When people want to volunteer to help, either as doctors or as teachers, has academic medicine provided a central clearing house to help match volunteers with needs? There seem to be "people to people" programmes and "doctors without borders," but these are not central organisations. Are all these concerns considered in academic public health, or are clinician-academicians involved?

Secondly, the pressure of research keeps us away from our students and patients. What is replacing the old fashioned rounds? I am especially concerned about computer workups and computerised grading. At times I have been asked to evaluate students on the basis of computerised writeups on patients I have not always seen. Is this a general trend, and how can it be opposed?

Lastly, the pressures on doctors and patients to use ever more expensive drugs seem unrelenting. Patients and their insurance companies will rebel and must rebel. This rebellion will collide with the desire of the drug companies for more profits. Academic doctors will be caught in the middle but will be inclined to side with the patients. Yet drug companies and academic centres have had an alliance that will now be strained and polarise doctors and drug companies, and doctors and patients.

Margaret S Terpenning associate professor, internal medicine

Geriatric Research Education and Clinical Center, 11G GRECC, VA Hospital, 2215 Fuller Road, Ann Arbor, MI 48103, USA mterpenn@umich.edu

Competing interests: None declared.

1 Tugwell P.Campaign to revitalise academic medicine kicks off. BMJ 2004;328:597. (13 March.)

\section{A road map needs to be drawn for the 21st century}

EDITOR-The international effort to revise and reform academic medicine is timely and appropriate.

In the past century the science of medicine has become a massive enterprise, fuelled by both government and industry money. But growth has also resulted in a separation of science from practitioners of the discipline. Most of today's major scientific health advances are created not by practising doctors but by people whose entire career is based in laboratories. Disciplinary boundaries in health care have become blurred so that many health professionals do well in roles previously thought to be medical roles. Several major reports have resulted in transformation in the processes of medical education so that curricula are now more student centred (problem based learning), more community based (to provide training in the milieu where practice will subsequently occur), and more inclusive of the social sciences than was the case in the past.

The 21st century calls out for new reforms. Scientific medicine must not only incorporate the contributions of "basic" scientists and, where available, clinical investigators but also build teams of many skills to deal with contemporary health problems. Both students and practitioners of medicine must see the relevance of research to their own work and perhaps contribute.

Globalisation requires that the fortunate medical schools in the developed world must partner with their colleagues in the developing world to ensure that educational standards and basic healthcare delivery are assured for all.

Instead of lengthening the medical school and residency curriculums to encompass new developments, medical educators 
must accept responsibility for the continuum of health education, moving beyond the initial four years of medical school and encompassing the entire learning lifetime of practising clinicians. If health professionals work in teams then they should also learn in teams to change health care. Faculty members engaged in team activities are currently not rewarded but a reward system must arise out of the new approaches to research and education.

Jean D Gray professor emeritus

Dalhousie University, Halifax, NS, Canada

B3M 2B3

jeangray@hfx.eastlink.ca

Competing interests: None declared.

1 Tugwell P. Campaign to revitalise academic medicine kicks off. BMJ 2004;328:597. (13 March.)

\section{Some thoughts for academic revisionists} to consider

EDITOR-Fundamental revision of academic medicine ${ }^{1}$ might start by considering:

- Expanding medicine's biomedical worldview to include the impacts of social, emotional, environmental, familial, and occupational factors on health and disease

- Expanding major educational venues beyond the hospital to doctors' offices, patients' homes, nursing homes, rehabilitation units, and hospices

- Replacing the emphasis on single "causes" for most diseases with profiles of predisposing, precipitating, and perpetuating factors that recognise clusters or sequences of the several elements required to evoke biological or behavioural changes-for example, genes, diet, and sedentary lifestyle for diabetes; strong coffee, ageing, and stress for atrial fibrillation; poverty, depression, and the tubercle bacillus for tuberculosis; climate change, stress, depression, and a virus for the common cold

- Requiring graduates to be knowledgeable about current concepts, methods, contributions, and limitations of clinical, biomedical, behavioural, and population perspectives in medicine

- Shrinking basic science courses and incorporating their principles in longer exposures focused on the rationales, relative efficacy, and costs for diagnostic, pharmacological, procedural, behavioural, and population interventions

- Requiring students to determine hospitalisation and annual prescription charges and costs for each patient

- Incorporating a short course by an aviation safety engineer on how "near misses," errors, and catastrophes are reported and managed

- Incorporating lecture/reading/study/ essay courses on the history of medicine and the scientific method and on works by doctors and nurses covering pain, suffering, deprivation, disability, and medical encounters

- Requiring students to write two papers ("acute" and "chronic" illnesses) discussing how the illness was first labeled; the diagnostic criteria; numbers and rates for each in their city, county, state, or province, and nation; how health departments obtain this information; the efficacy and individual and collective costs of interventions; who pays; and what is being done to prevent and limit the spread and deterioration of each disease.

Kerr $\mathbf{L}$ White retired deputy director for health sciences, Rockefeller Foundation, New York Charlottesville, VA 22911, USA Klw2j@virginia.edu

Competing interests: None declared.

1 Tugwell P. Campaign to revitalise academic medicine kicks off. BMJ 2004;328:597. (13 March.)

\section{Roll Back Malaria: a failing global health challenge}

\section{Options for malaria control need to be} weighed

EDITOR-Yamey says that only increased support from donor groups can save the Roll Back Malaria campaign. ${ }^{1}$ Three tools for malaria control are now offered for donors to support: nets, insecticides, and drugs. We should weigh our options before investing in each of these tools.

Malaria control programmes heavily based on insecticides are unsustainable by poor countries. Termination of external support for such programmes was followed by epidemics of malaria in communities that had lost their immunity during years of free insecticides. ${ }^{2}$

The bed net programmes in Africa have so far fallen far below expectations. With the spread of antimalarial drug resistance, provision of effective treatment is now assuming a more crucial role in determining the success or failure of malaria control.

Cheap firstline antimalarial drugs have now to be replaced by more expensive artemisinin based combination treatments. These are beyond the abilities of the national malaria programmes in endemic areas. If these countries get the donor support needed to make this crucial decision, and as more countries change to artemisinin based combination treatments, this could help to reduce the cost of these drugs and make them more affordable in endemic areas. ${ }^{3}$

Ahmed A Abdel-Hameed Adeel professor

Department of Pathology, College of Medicine, King Saud University, P O Box 2925, 11461

Riyadh, Saudi Arabia

aadeel@ksu.edu.sa

Competing interests: None declared.

1 Yamey G. Roll Back Malaria: a failing global health campaign. BMJ 2004:328:1086-7. (8 May))

2 Najer JA, $2004,328.1086-7$, (8 May.) eje JA, Kouznetsor RL, Delacollte C. Malaria epidemics detection and control forecasting an prevention. General. World Health Organization. www.rbm.who.int/docs/najera_epidemics/naj_toc.htm

3 World Health Organization. Improving the affordability and financing of artemisinin-based combination therapies. General. World Health Organization. Www.1bm.who. mc_upload $/ 0 / 000 / 016 / 745 / 37268 \_$_ACT_final2.pdf (accessed 27 May 2004)
Developing a market for bed nets and insecticides is problematic

EDITOR-As shown in Yamey's recent editorial on the failure of the Roll Back Malaria campaign, ${ }^{1}$ appropriate economic thinking for sustainable development in Africa continues to be ignored. Thus, the customer for bed nets is not the individual African but the large non-governmental organisation, whose orders are largely based on price, not quality.

Economic lessons show, however, that markets are developed by the quality of a product. People, even poor Africans, are prepared to pay for quality, and although it is true that not everyone can afford to buy nets, once a critical mass of users of impregnated nets has been established then non-net users are also protected.

Rather than insisting on a low price, non-governmental organisations could instead set the manufacturers of nets the more difficult target of producing, say, a permanently impregnated, durable net that works against Culex quinquefasciatus as well as anophelines.

Similarly, while the arguments rage over the possible reintroduction of dicophane (DDT), ${ }^{2}$ the Achilles' heel of many past and present indoor residual spraying programmes is people's refusal to have their houses sprayed, irrespective of the insecticide used.

The World Health Organization (WHO) issues guidelines to malaria control programmes so that workers know when to consider changing treatment as drug resistance increases. Perhaps WHO should do the same for malaria control programmes based on indoor residual spraying in the face of increasing refusal rates. At least DDT, because of its repellent effect, might provide some measure of personal protection to individual householders in the absence of a mass effect due to a high refusal rate among the population as a whole. But whether spraying an ever diminishing number of houses is the appropriate role for a malaria control programme is questionable.

J Derek Charlwood honorary fellow

Danish Bilharziasis Laboratory, Furvela,

Mozambique

dc@bilharziasis.dk

Competing interests: None declared.

\footnotetext{
1 Yamey G. Roll Back Malaria: a failing global health campaign. BMJ 2004;328:1086-7. (8 May.)

Rosenberg T. What the World needs now is DDT. New York Times 2004 April 11.
}

\section{Management of diastolic heart failure in older adults}

\section{Diagnosing diastolic dysfunction is complex}

EDITOR-The diagnosis of diastolic heart failure is far more complex than suggested by Ahmed in his 10-minute consultation article. ${ }^{1}$ You cannot take the absence of systolic dysfunction as evidence that diastolic dysfunction is present. 
The European Study Group's guidelines require that three conditions be satisfied simultaneously: there must be a clinical history or signs consistent with heart failure, systolic function must be normal or near normal, and there must be evidence of abnormal diastolic relaxation. ${ }^{2}$ The last condition is paramount-heart failure as a result of transient systolic dysfunction (with or without concomitant diastolic dysfunction) induced by either ischaemia or arrhythmia does not constitute diastolic dysfunction.

The assessment of diastolic function by the standard Doppler echo cardiography indices of the ratio of early (E) to late or atrial (A) ventricular filling velocities, mitral deceleration time, and isovolumetric relaxation time has been largely discredited. Petrie et al compared numerous published reference ranges for these and found wildly discordant results depending which range was applied to their study population. Newer non-invasive indices such as the $\mathrm{E} / \mathrm{E}^{\prime}$ ratio obtained by tissue Doppler imaging may offer a more reliable measure but have yet to be adopted into routine practice.

Andrew C McCulloch research fellow in cardiology Glasgow Royal Infirmary, Glasgow G4 OSF acmcculloch@clinmed.gla.ac.uk

Competing interests: None declared.

Ahmed A. Management of diastolic heart failure in older adults. BMJ 2004;328:1114. (8 May.)

2 European Study Group on Diastolic Heart Failure. How to diagnose diastolic heart failure. Eur Heart J 1998;19:9901003

3 Petrie MC, Hogg K, Caruana L, McMurray JJV. Poor concordance of commonly used echocardiographic measures of left ventricular diastolic function in patients with suspected heart failure but preserved systolic function: i there a reliable echocardiographic measure of diastolic dysfunction? Heart 2004;90:511-7.

4 Ommen SR, Nishimura RA, Appleton CP, Miller FA, Oh JK, Redfield MM, et al. Clinical utility of Doppler echocardiography and tissue Doppler imaging in the estimation of left ventricular filling pressures: a comparative simultaneous Doppler-catheterization study Circulation 2000;102:1788-94.

\section{B-type natriuretic peptide was not} mentioned

EDITOR-I am surprised that B-type natriuretic peptide was not mentioned in the 10-minute consultation by Ahmed on managing diastolic heart failure in older adults. ${ }^{1}$ A low concentration of B-type natriuretic peptide makes diastolic heart failure very unlikely. ${ }^{2-4}$ This test can be done quickly and easily in general practice.

Kieran M Walsh editorial registrar

bmjlearning.com, London WC1H 9JR

kmwalsh@bmjgroup.com

Competing interests: None declared.

Ahmed A. Management of diastolic heart failure in older adults. BMJ 2004:328:1114. (8 May)

2 Sagnella GA. Measurement and significance of circulating Sagnella GA. Measurement and significance of circulating
natriuretic peptides in cardiovascular disease. Clin Sci (Lond) 1998;95:519-29.

3 Maisel A. B-type natriuretic peptide levels: a potential novel "white count" for congestive heart failure.J Card Fail 2001:7:183-93.

4 Maisel A. B-type natriuretic peptide in the diagnosis and management of congestive heart failure. Cardiol Clin 2001;19:557-71.

\section{Author's reply}

EDITOR-I agree with McCulloch that diagnosing diastolic heart failure is complex. A detailed discussion of this complex topic was beyond the scope of my brief review.

The third criterion of the European Study Group on Diastolic Heart Failure (evidence of abnormal left ventricular relaxation, filling, diastolic distensibility, and diastolic stiffness) is important yet impractical in routine clinical practice. ${ }^{1}$ Vasan et al proposed that a more practical "probable" diagnosis of diastolic heart failure may be made in patients with clinical heart failure and normal or near normal systolic function but no objective evidence of diastolic dysfunction. ${ }^{2}$ Accordingly, I said that a probable diagnosis of diastolic heart failure can be made if echocardiography shows preserved systolic function. I also said that documentation of an abnormal left ventricular relaxation pattern would be required for a more specific diagnosis. I mentioned the ratio of early (E) to late or atrial (A) ventricular filling velocities along with its limitations as it is one of the most commonly used echocardiographic indices for diastolic dysfunction. Discussion of the comparatively new tissue Doppler imaging technique was beyond the scope of this brief review for generalist doctors.

I also agree with Walsh about the potential for B-type natriuretic peptide as a diagnostic tool. However, its use in diagnosing diastolic dysfunction is still evolving and is not recommended by major heart failure guidelines. ${ }^{3}{ }^{4}$ In managing complex problems such as heart failure with rapidly evolving diagnostic and therapeutic strategies, generalist doctors might best follow specific guideline recommendations.

Ali Ahmed assistant professor

Division of Gerontology and Geriatric Medicine,

School of Medicine, University of Alabama at Birmingham, Birmingham, AL, USA aahmed@uab.edu

1 European Study Group on Diastolic Heart Failure How to diagnose diastolic heart failure. Eur Heart J 1998;19:9901003

2 Vasan RS, Levy D. Defining diastolic heart failure: a call for standardized diagnostic criteria. Circulation 2000;101:2118-2

3 Remme WJ, Swedberg K. Guidelines for the diagnosis and treatment of chronic heart failure. Eur Heart $J$ 2001;22:1527-60.

4 Hunt SA, Baker DW, Chin MH, Cinquegrani MP, Feldman AM, Francis GS, et al. ACC/AHA guidelines for the evaluation and management of chronic heart failure in the adult: executive summary. A report of the American College of Cardiology/American Heart Association Task Force on Practice Guidelines (Committee to revise the 1995 Guidelines for the Evaluation and Management of Heart Failure).J Am Coll Cardiol 200 1;38:2101-13.

\section{Effect of public smoking ban in Helena, Montana}

\section{When results look too good to be true, they probably are}

EDITOR-As a cancer researcher who has published extensively on the harmful effects of smoking, I am in favor of vigorous smok-

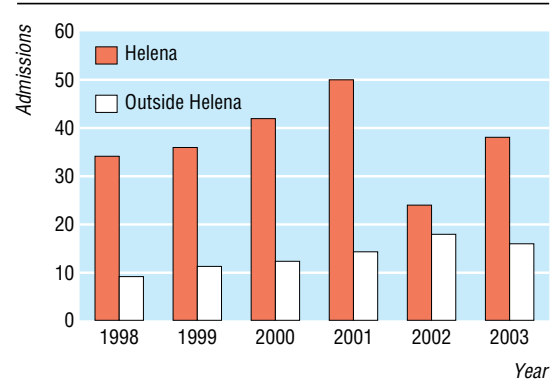

Admissions for acute myocardial infarction during six month periods June-November before, during (2002), and after smoke-free3 ordinance was implemented in Helena alone on 5 June 2002

ing bans. However, the study by Sargent et al, claiming that the six month smoking ban in Helena, Montana, was associated with an immediate $40 \%$ drop in heart attacks must be viewed with scepticism.

Firstly, the researchers had no information on whether exposure to second hand smoke changed as a result of the ban. They also did not present any information on whether smoking habits were affected by the ban. If the study was concerned to isolate an effect of second hand tobacco smoke, it should have been restricted to the $33 \%$ of the study population who were never smokers.

Secondly, the drop in heart attacks is based on very few cases: four per month on average during the ban, compared with seven per month before. Because of these small numbers the reported difference could easily be due to chance or to some uncontrolled factor.

Finally, the "immediate effect" should make anyone stop and question the connection the authors are asserting. There are few interventions in public health that have such an immediate impact. Even if all active smokers in Helena had quit smoking for at least a year, one would not expect to see such a dramatic effect.

The attempt to make claims about the effects of smoking bans based on this very weak ecological study raises disturbing questions about our ability to distinguish between sound science and wishful thinking.

Geoffrey Kabat epidemiologist

16 Bon Air Avenue, New Rochelle, NY 10804, USA gck1@optonline.net

Competing interests: None declared.

\section{Sargent RP, Shepard RM, Glantz SA. Reduced incidence of admissions for myocardial infarction associated with pub- lic smoking ban: before and after study [with commentary April.)}

\section{Can law really make a difference?}

EDITOR-In the study by Sargent et al conducted at Helena, Montana, admissions in people with acute myocardial infarction during the smoking ban seem to have fallen, implying the possible effects of smoking on 
the heart. ${ }^{1}$ What is more distressing, however, is that, despite the general awareness of the ill effects of smoking, people petitioned for the ban to be removed within six months. The effect of nicotine was a stronger driving force than the law.

Although the number of admissions fell, several factors should be considered. The first is the number of cases that were actually exposed to smoke both actively and passively in the control and study groups. The second is whether patients with premorbid conditions were comparable in both groups. The third is whether the study numbers are really representative of a much larger population.

The study does offer a ray of hope that if more definite and extensive studies show significant outcomes, the reality of having a wider ban on smoking may be possible to make a difference for non-smokers.

Sheena Surindran clinical observer

Kettering General Hospital, Kettering,

Northamptonshire NN16 8UZ

drssurin@yahoo.com

Competing interests: None declared.

Sargent RP, Shepard RM, Glantz SA. Reduced incidence of admissions for myocardial infraction associated with public smoking ban: before and after study [with commentary by T Pechacek and S Babb]. BMJ 2004;328:980.
(24 April.)

\section{Author's reply}

EDITOR-We present a simple observation: when Helena, Montana, implemented a smoke free law admissions for myocardial infarction dropped significantly, then rebounded when the law was suspended through a lawsuit by tobacco industry allies.

Kabat makes the usual arguments of scientists who have worked with the tobacco industry. ${ }^{1-3}$ Rather than taking our paper at face value, he tells us we should have done a different study. He ignores the evidence (cited in our paper) that exposure to smoke falls when such laws are in effect. He ignores our discussion and the accompanying commentary by Pechacek and Babb, which provided the biological explanation of why the rapid drop we observed would be expected. He also failed to disclose his ties to the tobacco industry. ${ }^{3}$

Yes the numbers are small because, as we point out in the paper, the fact that Helena is a small isolated community is what made the study possible. Small numbers make it harder to detect an effect when it exists; the fact that we detected a statistically significant drop in admissions when the law was in effect despite the small numbers is a strength, not a weakness, of the study.

Surindran raises interesting questions that will require larger studies to answer. As we said in our paper, we believe that the effect we found was due to a combination of much lower exposure to second hand smoke and people stopping smoking because of the smoke free environments. ${ }^{4}$ We agree with Surindran that our results indicate that smoke free policies would make a difference for non-smokers.

Stanton A Glantz professor of medicine

Division of Cardiology, Department of Medicine,

University of California, San Francisco, CA

94143-1390, USA

glantz@medicine.ucsf.edu

Competing interests: None declared.

1 Fields N, Chapman S. Chasing Ernst L Wynder: 40 years of Philip Morris' efforts to influence a leading scientist. $J$ Epidemiol Community Health 2003;57:571-8.

2 Thun M. More misleading science from the tobacco industry: Delaying clean air laws through disinformation. $B M J$ USA 2003;3:352-3

3 Bero L, Glantz S, Hong M. The limits of competing interest disclosures. Tobacco Control. (In press.)

Ong M, Glantz S. Cardiovascular and health effects of smoke free workplaces. Am J Med. (In press.)

\section{Eating more vegetables might explain reduced asthma symptoms}

EDITOR-Anderson et al report a decrease in the prevalence of asthma symptoms among 12-14 year olds in the British Isles. ${ }^{1}$

In a community survey in rural China we examined the risks of asthma and wheeze in relation to fresh vegetable consumption among lifelong non-smokers. All residents $(\mathrm{n}=38$ 109) in three townships (Yijing, Huigong, Fushan) of Zongyang County were visited by trained interviewers in 1993 , and those aged $>15$ years $(n=21649)$ completed a standard questionnaire about smoking habits, dietary intake, and respiratory symptoms.

Only 218 cases of doctor diagnosed asthma were identified in 16460 children aged $\leq 14$ years (prevalence $1.32 \%$ ) and 290 in those aged $15-84$ years $(1.34 \%$ prevalence). Overall, $31.5 \%(160 / 508)$ of those with asthma had a history of allergy.

Among those aged 15-34 years, the prevalence of asthma increased with lower consumption of vegetables over the previous year ( $\mathrm{P}$ for trend=0.04). After adjustment for age, sex, educational level, body mass index, occupation, exposure to dust at work, presence of cooking oil smoke in bedroom, and type of fuel used, the odds ratio of diagnosed asthma was 1.5 (95\% confidence interval 0.4 to 4.8$)$ in those who ate vegetables twice or more weekly but less than once daily (3/389 subjects) and 3.5 (1.1 to 11.7) in those who ate vegetables once a week or less (3/172) compared with those who ate vegetables daily (44/8530). We found no such association in those aged 35-84 (6/436, 2/149, and 126/6961 respectively; multiple adjusted odds ratio 0.8 (0.4 to 1.9$)$ and $0.7(0.2$ to 2.9$))$. Wheeze showed similar associations.

Our finding that the risk of asthmatic symptoms increased with low fresh vegetable consumption in young Chinese people, who would be more likely to have changed their dietary habits because of the rapid economic advances in China since 1978, further support the concept of a protective effect of vegetables and antioxidant vitamins on asthma. ${ }^{2-4}$ This, together with an increase in vegetable and fruit consumption in schoolchildren in the United Kingdom during the past decade, ${ }^{5}$ may partly explain both the low prevalence in countries with traditional dietary habits and the rise in asthma in Britain since the 1950 s that is now decreasing. ${ }^{1}$

Ruoling Chen honorary senior lecturer

Department of Epidemiology and Public Health, University College London, London

WC1E 6BT

ruoling.chen@westminster-pct.nhs.uk

Zhi Hu professor of health administration and

epidemiology

School of Health Administration, Anhui Medical University, Hefei, Anhui 230032, China

Anthony Seaton emeritus professor of environmental and occupational medicine

Department of Environmental and Occupational

Medicine, University of Aberdeen, Aberdeen

Medicine,

Competing interests: None declared.

1 Anderson HR, Ruggles R, Strachan DP, Austin JB, Burr M, Jeffs D, et al. Trends in prevalence of symptoms of asthma, hay fever, and eczema in 12-14 year olds in the British Isles, 1995-2002: questionnaire survey. $B M J$ 2004;328:1052-3. (1 May.)

2 Seaton A, Godden DJ, Brown K. Increase in asthma: a more toxic environment or a more susceptible population? Thorax 1994;49:171-4.

3 Bodner C, Godden D, Brown K, Little J, Ross S, Seaton A Antioxidant intake and adult-onset wheeze: a case-control study. Eur Respir J 1999;13:22-30.

4 Hijazi N, Abalkhail B, Seaton A. Diet and childhood asthma in a society in transition; a study in urban and rural Saudi Arabia. Thorax 2000; 55:775-779.

5 Inchley J, Todd J, Bryce C, Currie C. Dietary trends among Scottish schoolchildren in the 1990s. J Hum Nutr Die 2001;14:207-16.

\section{The power of five}

EDITOR-I write with reference to Spence's personal view on what he calls the two dimensional model of medical correctness.

When the chief medical officer recommended recently that we should all take 30 minutes exercise five times a week, I found myself wondering whether we should be eating our five daily portions of fruit and vegetables while we were doing our exercise or not.

Surely we should be told.

Neville W Goodman consultant anaesthetist Southmead Hospital, Bristol BS10 5NB Nev.W.Goodman@bris.ac.uk

Competing interests: None declared.

1 Spence D. Are we creating a health pariah class? BMJ 2004;328:1141. (8 May)

\section{bmj.com}

Letters appearing here are an edited selection of rapid responses originally posted on bmi.com

We ask for all letters to the editor to be submitted as rapid responses via bmj.com

For advice see: bmj.com/rapidresponses 